\title{
- Head and Neck Mucormycosis Infections - Our Experiences
}

\section{IJCRR \\ Section: Healthcare \\ ISI Impact Factor \\ (2019-20): 1.628 \\ IC Value (2019): 90.81 \\ $\operatorname{SJIF}(2020)=7.893$ \\ (c) (i) (3) \\ Copyright@IJCRR}

\section{Swain SK ${ }^{1}$, Jena PP², Bhuyan $\mathbf{R}^{3}$}

\begin{abstract}
'Department of Otorhinolaryngology and Head \& Neck Surgery, IMS and SUM Hospital, Siksha "O” Anusandhan University, K8, Kalinganagar, Bhubaneswar-751003, Odisha, India; 'Department of Microbiology, IMS and SUM Hospital, Siksha "O” Anusandhan University, K8, Kalinganagar, Bhubaneswar-751003, Odisha, India; ${ }^{3}$ Medical Research Laboratory, IMS and SUM Hospital, Siksha "O” Anusandhan University, K8, Kalinganagar, Bhubaneswar-751003, Odisha, India.
\end{abstract}

\section{ABSTRACT}

Introduction: An uncommon therapeutic entity is mucormycosis and immunocompromised patients are often affected by this infection. This fungus is under the order of the Mucorales. The Rhizopus genus is the most common causative organism related to mucormycosis. It is an acute disorder and there is a poor prognosis.

Objective: To study the experiences of mucormycosis treatment at our tertiary care teaching hospital over the last three years in the head and neck area.

Materials and Methods: A retrospective research involved 8 patients diagnosed with mucormycosis of the head and neck over 3 years between January 2019 and February 2021.

Results: There are 5 male and 3 female patients, aged between 29 to 65 years. Out of 8 patients, 4 were diabetic and the rests were with haematological disorders. There were 5 sinonasal mucormycosis and 3 non-sinonasal involvement. Diagnoses were established by histopathological study. In this study, two patients faced cerebral involvement.

Conclusion: The early diagnosis and recovery from this infection are enhanced by early diagnosis with a tissue biopsy, local management of the disease by urgent surgical debridement and adequate systemic antifungal treatment. Mucormycosis therapy includes antifungal agents such as Amphotericin B and broad surgical debridement. Early diagnosis and care are also required for patients to survive.

Key Words: Mucormycosis, Head and Neck, Sinonasal area, Immunocompromised patient, Amphotericin B, Surgical debridement

\section{INTRODUCTION}

Mucormycosis is an uncommon and feared disease, caused by a fungus of the order Mucorales. It has increased the chance of mortality and morbidity. It is an opportunistic infection of fungi. Paltauf first described mucormycosis in $1885 .{ }^{1}$ which is harmless to a healthy person but lethal in immunocompromised patients. It is also known as Zycomycosis. Rhizopus is most often the causative organism in mucormycosis. Diabetic and neutropenic ketoacidosis are typical predisposing disorders. This virus is life-threatening and has a remarkable preference for the arteries. They tend to spread into vessels and lymphatics causing the formation of Mucor thrombi and leads to ischemia and infarction of the affected tissue. ${ }^{2}$ This fungal infection usually dissects the internal elastic lamina from the blood vessel media, causing significant endothelial damage and contributing to thrombosis. Mucormycosis is categorized by anatomical positions such as rhino maxillary, central nervous system, cutaneous, pulmonary, disseminated and miscellaneous in multiple ways. The rhino-orbit-cerebral is the most prevalent type of mucormycosis. ${ }^{3}$ Paranasal sinuses (39\%), Brain (9\%) and gastrointestinal (7\%) forms and other miscellaneous varieties are the most common types of mucormycosis infections. ${ }^{4}$ The optimal therapy includes correction of underlying risk factors, antifungal treatment with Amphotericin-B. Here we present our experiences of mucormycosis treatment at our tertiary care teaching hospital over the last three years in the head and neck area.

\section{MATERIALS AND METHODS}

Eight patients were treated in the department of Otorhinolaryngology between January 2019 to February 2021. Four

\section{Corresponding Author:}

Swain SK, Professor, Department of Otorhinolaryngology and Head \& Neck Surgery, IMS and SUM Hospital, Siksha "O” Anusandhan University, K8, Kalinganagar, Bhubaneswar-751003, Odisha, India; Cell: +91-9556524887; Email: santoshswain@soa.ac.in

ISSN: 2231-2196 (Print)

Received: 16.01 .2021
ISSN: 0975-5241 (Online)

$$
\text { Revised: } 17.02 .2021
$$

Accepted: 14.03 .2021 
patients were referred from the department of hemato-oncology and the rest four were referred from the endocrinology/Diabetology department. Clinical features, radiological findings, histopathological reports and treatment were recorded and analyzed. This research study was accepted by the Institutional Ethics Committee (IEC). Both four patients with diabetic Mellitus were routinely administered with oral hypoglycemic agents/insulins, but their blood glucose was poorly controlled. Diagnostic nasal endoscopy was done in all patients showed details of nasal cavity and nasopharynx. Ophthalmological consultation was done in all participants to find out lose vision or not. To check any spread to the orbit and neighbouring facial region, computed tomography (CT) scans of the nose and paranasal sinuses were performed. A biopsy sample (Fig 1) was taken from both cases displaying the mucormycosis illustration with some non-septate fungal hyphae focuses on right-angled hyphae divisions (Fig 2). In two cases accompanied by parenteral amphotericin B $(0.5$ $\mathrm{mg} / \mathrm{kg} / \mathrm{day}$ ), both were subjected to radical mucormycosis excision along with orbital exenteration. Patient follow-up was performed six months after surgery.

\section{RESULTS}

Out of the 8 patients, there are 5 male and 3 female patients, aged from 29 to 65 years. The mean age of the patients in this study is $51.5 y e a r s$. Out of 8 patients, 4 were diabetic. All four patients were uncontrolled diabetes mellitus which was diagnosed for the first time. All the patients were from poor socio-economic classes. Four patients were farmers, three were roadside vendors and one was a retired teacher. There were 5 sinonasal mucormycosis and 3 non-sinonasal involvement. Out of three non-sinonasal mucormycosis, one was palatal involvement, one was orbito-facial and the last one was otogenic. All patients with sinonasal mucormycosis presented with foul-smelling nasal discharge and nasal block. Diplopia was seen in 1 patient, the headache was presented in 3 patients, septal perforation in 1 patient, palatal perforation (Fig.3) in 1 patient and cellulitis of the facial area in 2 patients. One patient had orbito-facial swelling (Fig.4). One patient had lower cranial nerve paralysis. All participants had more than one clinical presentation. All patients with sinonasal mucormycosis showed black necrotic debris inside the nasal cavities. The diagnosis was established by histopathological study. The nasal discharge was cultured which showed Rhizopus oryzae in six patients and the rest revealed no growth. Two patients were fatal because of their cerebral involvement. All patients with diabetes mellitus were managed by controlling blood sugars and all attained a normal level of blood sugar. All patients have undergone debridement under general anaesthesia. All patients were administered an intravenous infusion of amphotericin-B. The initial dose was $0.5 \mathrm{mg} / \mathrm{kg} /$ day of amphotericin-B. The Amphotericin-B was given as an intravenous route in 5\% dextrose and later on the dose was adjusted based on patient tolerance and response. The deaths of the two patients were died in the hospital due to intracranial involvement. Details of clinical descriptions of the head and neck mucormycosis are given in Table 1. One patient had permanent vision loss in one eye and one had residual vision loss. One patient lost to follow up and the remaining were disease-free.

\section{DISCUSSION}

Mucormycosis is caused by several genera of saprophytic fungi connected to Phycomycetes (zygomycetes) and order Mucorales. ${ }^{5}$ The fungus is very close to the arteries and adheres to the arterial wall. It forms around the blood vessels' inner elastic lamina, causing thrombosis, ischemia and necrosis of the underlying tissues. Mucorales are abundantly seen in soil, plants that rot, animal excreta and foodstuffs. ${ }^{6}$ In humid conditions, they emerge quickly and the sporangiospores are released into the atmosphere and dispersed as airborne propagules. The incidence of mucormycosis in the head and neck region is not related to sex or age. ${ }^{7}$ There are three different modes of transmission like inhalation, ingestion and percutaneous introduction spores of mucormycosis. There is no person-to-person spread of mucormycosis. In India, airborne spores are more suitable for fungal development during the transition from summer to the rainy season. ${ }^{8}$ Mucormycosis is an unusual clinical disease that also affects immunocompromised patients. Fungi, mostly from the genus Rhizopus or Mucor, are the species that cause Mucormycosis, Rhino-orbital-cerebral and pulmonary infections can result in mucormycosis, and both forms of diseases can lead to patients being in an emergency condition. ${ }^{9}$ Rhinocerebral mucormycosis is a rapidly spreading disease with a high mortality rate that needs immediate surgical debridement followed by medical intervention..$^{10}$ In our case, five cases were sinonasal variety whereas the rests three were nonsinonasal types like isolated orbito-facial, palatal and otogenic. The disorder only affects the orbit and nearby facial region of our orbito-facial variety without involving the nose and sinuses. Mucormycosis often spread to orbit and adjacent areas or the cranium either directly or via vial vessels. The mucormycosis may result in cavernous sinus thrombosis leading to either one side or both sides vision loss even within few hours. Mucormycotina is seen as common saprobes over decaying organic material and forest or agricultural soils. These are rapidly growing organisms with no or only a few septae, characterized by ribbon-like hyphae. Cunninghamella, Absidia (Lichtheimia), Mucor, Rhizomucor, Rhizopus and one of the geographic distribution bases, Saksenaea and Apophysomyces are the genera affecting humans. ${ }^{11}$ In immunocompromised hosts, such as patients with haematological malignancies or those receiving hematopoietic stem cell transplantation, these aggressive and highly destructive fungal infections are more often seen. Ketoacidosis 
and transfusion/dyserythropoietic iron overloaded patients are also important risk groups for diabetic Mellitus. Uncontrolled diabetes mellitus, particularly with a history of ketoacidosis, is the most important predisposing factor associated with mucormycosis. ${ }^{12}$ This deadly disorder could be at risk for vulnerable farmers with untreated and undiagnosed diabetes mellitus. Four of our patients $(50 \%)$ were farmers with untreated and undiagnosed diabetes mellitus. Farmers those uses organic manure are more prone for this disease as organic manure often contain animal excreta and decayed substance which has a high concentration of Mucorales. During applying manure in the farming field, there are chances of inhalation of fungal spores. Three patients $(37.5 \%)$ were street fast food vendors who were working near to dustbin containing decaying food materials that act as a good source of Mucorales particularly in a humid environment. Often, predisposing factors include neutropenia, immunosuppressive therapy, acquired immune deficiency disease, starvation, dialysis, haematological malignancy and organ transplantation. Mucormycosis affects immunocompromised patients universally. As in organ transplantation, the powerful T-cell depleting agents used for immunosuppression also contribute to a high risk of inducing mucormycosis, while mucormycosis is widespread and quickly expanding, an immunologically capable patient is rarely affected. In patients with extreme underlying disorders such as diabetic Mellitus, leukaemia, organ transplants, acquired immunodeficiency syndrome, severe burns, and immunosuppressive drugs, mucormycosis exists, about 70 to 80 per cent of patients with mucormycosis have diabetes mellitus. ${ }^{13}$ Radiological imaging will not determine the diagnosis of mucormycosis but will indicate it. Computed tomography(CT) or Magnetic resonance imaging(MRI) is useful for mucormycosis facial and cerebral involvement and assesses loco-regional expansion to the orbit and brain and recognizes cerebral thrombosis as well. ${ }^{14}$ The presence of cavernous sinus is better measured by MRI. ${ }^{12}$ Screening challenges and follow-up with antifungal therapy and susceptibility to certain widely used antifungal agents contribute to increased mortality in some patient classes. ${ }^{15}$ Except for histopathological evidence, there is no other definitive diagnosis for mucormycosis by seeing the non-septate hyphae of the infected tissue. ${ }^{16}$ Necrosis of the underlying tissue prevents the entrance into the infection site of antifungal drugs such as amphotericin B. ${ }^{17}$ Early debridement of the infected tissue has a stronger prognosis for mucormycosis to be successfully treated. ${ }^{18}$ Treatment with liposomal amphotericin B has increased tissue penetration and is used as first-line therapy. ${ }^{3}$ However, monotherapy such as surgery alone or Amphotericin B alone has limited efficacy, whereas treatment is recommended for combination therapy with liposomal amphotericin B or posaconazole and surgical debridement. ${ }^{19}$ Amphotericin B has potential renal function toxicity, so the dose should be individually adjusted from $0.5 \mathrm{mg} / \mathrm{kg} /$ day to $1.0 \mathrm{mg} / \mathrm{kg} /$ day based on the patient's body weight and renal function. The total cumulative dose of Amphotericin B is 2 to $4 \mathrm{~g}$, often recommended in adults. Hyperbaric oxygen therapy acts as an adjuvant treatment and certain cytokines such as GM-CSF and interferon-gamma are under evaluation. Hyperbaric oxygen treatment has a static effect on fungi and helps revascularize the necrotic or ischemic tissue. ${ }^{20} \mathrm{New}$ antifungal agents and combination therapy have enhanced the survival rate of patients with mucormycosis. The overall mortality rate of patients with mucormycosis remains high due to delay in diagnosis, despite progress in treatment modality and care. More than five days of delayed diagnosis of mucormycosis is associated with an increased chance of death. ${ }^{21}$ In combination, correction of predisposing factors, timely diagnosis, surgical debridement and systemic anti-fungal are required for a successful result. Systemic Amphotericin B has its side effects that need to be handled closely. Amphotericin B in the classic form of desoxycholate at a dosage of $1-1.5 \mathrm{mg} / \mathrm{kg} /$ day or, more preferably, liposomal Amphotericin B is extremely effective for mucormycosis. The liposomal type has less nephrotoxicity and thus provides for longer cycles with higher doses of 5 to $15 \mathrm{mg} / \mathrm{kg} /$ day. Better concentrations of liposomal type in macrophages, like deeply infected tissue with greater CNS penetration. ${ }^{22} \mathrm{~A}$ new form of triazole, posaconazole, is effective in cases of failure with improved effectiveness in-vitro and in-vivo with strong tolerance and much lower side effects. Isavuconazole, a new form of expanded triazole spectrum, has been approved for the treatment of invasive aspergillosis and mucormycosis and works against moulds, yeast and dimorphic fungi. ${ }^{23,24}$ The average length of therapy with antifungal medications for mucormycosis varies with development but is prescribed for at least 12 weeks. ${ }^{14}$ The risk factors should be adequately handled to avoid mucormycosis. Patients with uncontrolled diabetes mellitus and require very close management to avoid this feared disorder are also seen with mucormycosis.

\section{CONCLUSION}

An unusual and dreaded fungal infection in the area of the head and neck is mucormycosis. It is a quickly progressing condition with a fatal result unless promptly diagnosed and treated early. Fatal complications and death can result from delayed diagnosis and treatment. Treatment requires both surgical and medical services. Amphotericin B needs early and appropriate care, surgical resection and risk factors management may improve prognosis. Prognosis relies on many variables and includes the early start of therapy. For the effective treatment of patients with mucormycosis, a multi-modality approach is usually required and it includes otolaryngologists, ophthalmologists, neurologists and dental surgeons. Risk factor detection and all preventive steps will minimize the occurrence of life-threatening mucormycosis in the region of the head and neck. 
Acknowledgement: None

Funding: Nil

\section{Conflict of interest: Nil}

Author Contribution: Prof.Santosh Kumar Swain: Concept, data collection and data analysis; Dr.Pragnya Paramita Jena: Data collection and drafting; Dr.Ruchi Bhuyan: Data collection.

\section{REFERENCES}

1. ArasMH, Kara MI, Erkiliç S, Ay S. Mandibular Mucormycosis in Immunocompromised Patients: Report of 2 Cases and Review of the Literature. J Oral Maxillofac Surg. 2012; 70(6):13621368.

2. Swain SK, Sahu MC, Banerjee A. Non-sinonasal isolated facial-orbital mucormycosis-a case report. J Mycologie Med. 2018;28(3):538-541.

3. Viterbo S, Fasolis M, Garzino-Demo P, Griffa A, Boffano P, Iaquinta $\mathrm{C}$, et al. Management and outcomes of three cases of rhinocerebral mucormycosis. Oral Surg, Oral Med, Oral Pathol, Oral Radiol, Endod. 2011;112(6):69-74.

4. Chamilos G, Lewis RE, Kontoyiannis DP. Delaying Amphotericin B-based frontline therapy significantly increases mortality among patients with hematologic malignancy who have zygomycosis. Clin Infect Dis. 2008; 47(4): 503-509.

5. Pinto ME, Manrique HA, Guevara X, Acosta M, Villena JE, Solís J. Hyperglycemic hyperosmolar state and rhino-orbital mucormycosis. Diabetes Res Clin Pract. 2011;91(2):37-39.

6. Swain SK, Sahu MC, Baisakh MR. Mucormycosis of the Head and Neck. Apollo Med.2018;15(1):6-10.

7. Ibrahim M, Chitnis S, Fallon K, Roberts T: Rhinocerebral mucormycosis in a 12-year-old girl. Arch Neurol2009; 66(2): 272-273.

8. Babu SV, Venkatesh U, Prasannaraj T, Shivaprakash VK, Prathima S. Sinonasal mucormycosis: A series of seven cases. Clinical Rhinology: An Int J.2014(2):28-30.

9. Kauffman CA, Malani AN. Zygomycosis: an emerging fungal infection with new options for management. Curr Infect Dis Rep. 2007; 9(6): 435-440.

10. Swain SK, Lenka S, Das SR. Rhino-orbital Mucormycosis-A Dreaded Clinical Entity. Int J Cur Res Rev.2020;12(24):197-203.

11. Jestin M, Azoulay E, Pène F, Bruneel F, Mayaux J, Murgier M, et al. Poor outcome associated with mucormycosis in critically

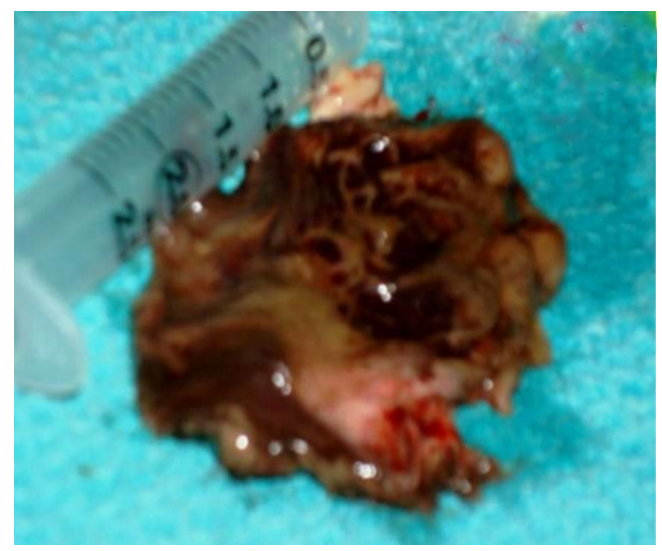

Figure 1: Black necrotic mass from nasal cavity sent for histopathological examination. ill haematological patients: results of a multicenter study. Ann of Intensive Care2021;11(1):1-8.

12. Wali U, Balkhair A, Al-Mujaini A. Cerebro-rhino orbital mucormycosis: an update. J Infect Public Health 2012; 5(2): 116-126.

13. Hsiao YC, Tsan KW, Wang TY. Rhinocerebral Mucormycosis in Diabetes - A Case Report. J Intern Med Taiwan 2002; 13(1): 160-164

14. Lmekki S, Zaki Z, El Alami MN. Mucormycose rhinocérébrale. Med Mal Infect2012; 42(4):171-173.

15. Mohammadi R, Nazeri M, Sayedayn SM, Ehteram H. Successful treatment of rhinocerebral mucormycosis due to Rhizopus oryzae. J Res Med Sci2014; 19(1): 72-74.

16. Skiada A, Pagano LI, Groll A, Zimmerli S, Dupont B, Lagrou K, et al. Zygomycosis in Europe: analysis of 230 cases accrued by the registry of the European Confederation of Medical Mycology (ECMM) Working Group on Zygomycosis between 2005 and 2007. Clin Micro and Infect 2011;17(12):1859-1867.

17. Lanternier F, Sun HY, Ribaud P, Singh N, Kontoyiannis DP, Lortholary O. Mucormycosis in organ and stem cell transplant recipients. Clinical infectious diseases2012;54(11):1-8.

18. Lai MC, Zhang W, Yang Z, Zhang W, Owusu-Ansah KG, Yu SF, et al. First case report of isolated penile mucormycosis in a liver transplantation recipient. Int $J$ Infect Dis 2014;29(1):208-210.

19. Chakrabarti A, Das A, Sharma A, Panda N, Das S, Gupta KL, et al. Ten years' experience in zygomycosis at a tertiary care centre in India. J of Infect. 2001;42(4):261-266.

20. Almannai M, Imran H, Estrada B, Siddiqui AH. Successful treatment of rhino-orbital mucormycosis with posaconazole and hyperbaric oxygen therapy.Pediatr Hemato Oncol 2013; 30(3): 184-186.

21. Farojov R, Aydin O, Yilmaz C, Iakobadze Z, Do_ganay L, Caml1 D, et al. Rhino-Orbita-Maxillary Mucormycosis After Liver Transplantation: A Case Report.Transplantation Proceedings2016;48(9): 3210-3213.

22. Kim JG, Park HJ, Park JH, Baek J, Kim HJ, Cha IH, et al. Importance of immediate surgical intervention and antifungal treatment for rhinocerebral mucormycosis: a case report. J Korea Asso Oral Maxillofac Surg. 2013;39(5):246-250.

23. Graves B, Orla Morrissey C, Wei A, Coutsouvelis J, Ellis S, Pham A, et al. Isavuconazole as salvage therapy for Mucormycosis. Med Mycology Case Rep2016; 11(1):36-39.

24. Swain SK, Debta P. Aspergillosis of the palatine tonsil. Ann of Indian Academy of Otorhinolaryngol Head and Neck Surg. 2020;4(2):5052.

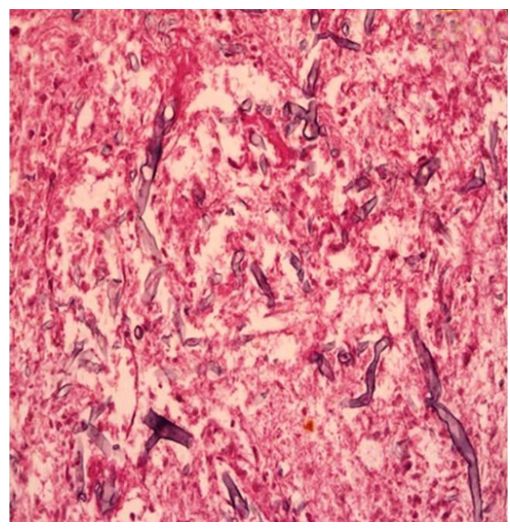

Figure 2: Histopathology microphotograph showing broad non-septate hyphae with $90^{\circ}$ branching (Eosin stain and 400X magnification). 


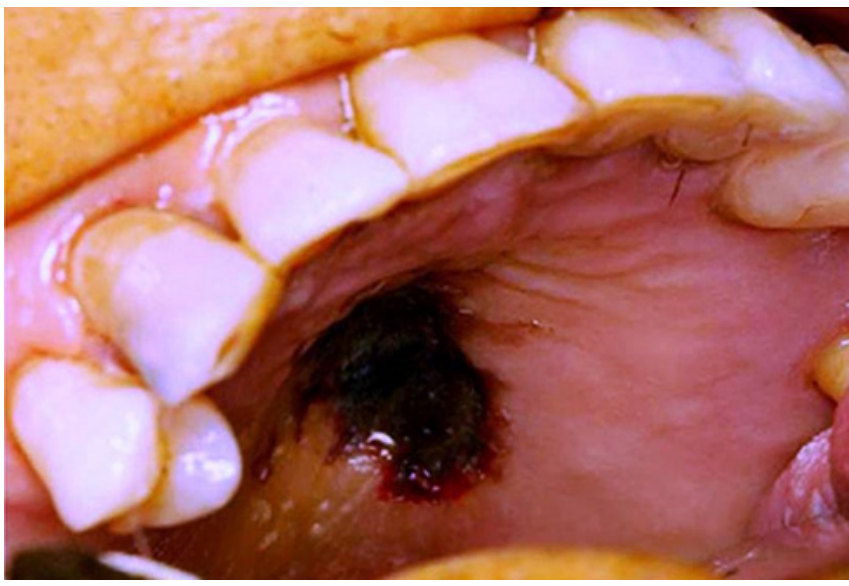

Figure 3: Mucormycosis affecting the hard palate.

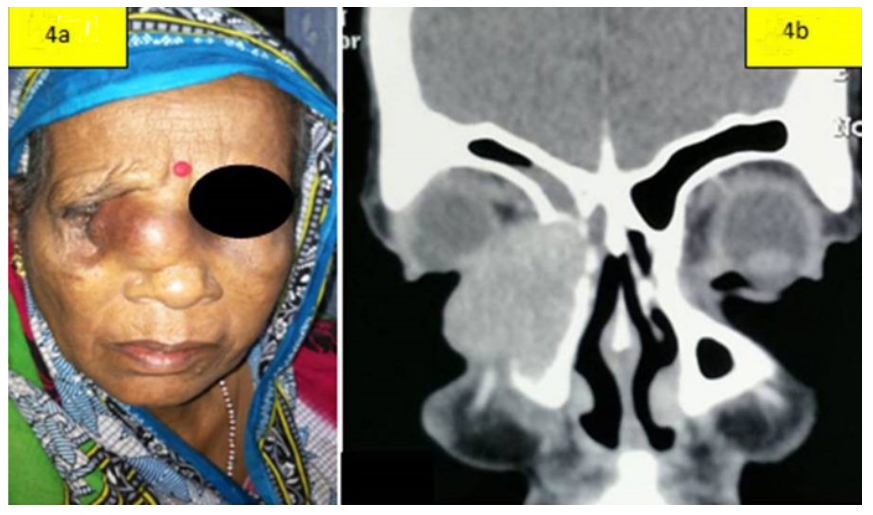

Figure 4: 4a: Mucormycosis mass at right facio-orbital area;4b: CT scan picture of the nose and paranasal sinuses showing mucormycosis mass at right facio-orbital region.

Table 1: Detail clinical presentations of Head and neck mucormycosis.

\begin{tabular}{|c|c|c|c|c|c|c|c|}
\hline $\begin{array}{l}\text { Patient } \\
\text { serial }\end{array}$ & Sex & Age & Affected part & $\begin{array}{l}\text { Clinical presenta- } \\
\text { tions }\end{array}$ & Primary disease & Treatment & Outcome \\
\hline 1 & $\mathrm{~F}$ & 65 & Orbito-facial & Headache & $\begin{array}{l}\text { Chronic myeloid } \\
\text { leukemia }\end{array}$ & $\begin{array}{l}\text { Surgical debridement, } \\
\text { Amphotericine-B }\end{array}$ & Cured \\
\hline 2 & M & 59 & Sinonasal & $\begin{array}{l}\text { Facial pain and } \\
\text { septal perforation }\end{array}$ & $\begin{array}{l}\text { Uncontrolled } \\
\text { diabetes }\end{array}$ & $\begin{array}{l}\text { Endoscopic debride- } \\
\text { ment plus amphoteri- } \\
\text { cine-B }\end{array}$ & Cured \\
\hline 3 & $\mathrm{~F}$ & 63 & Oro-sinonasal & $\begin{array}{l}\text { Facial pain and } \\
\text { palatal perforation }\end{array}$ & Aplastic anemia & $\begin{array}{l}\text { Surgical debridement } \\
\text { plus amphotericine-B }\end{array}$ & $\begin{array}{l}\text { Death after } \\
6 \text { months due } \\
\text { to Aplastic } \\
\text { anemia }\end{array}$ \\
\hline 4 & $\mathrm{~F}$ & 41 & $\begin{array}{l}\text { Sinonasal-or- } \\
\text { bito-cerebral }\end{array}$ & $\begin{array}{l}\text { Diplopia, headache } \\
\text { and lower cranial } \\
\text { nerve palsy }\end{array}$ & $\begin{array}{l}\text { Uncontrolled } \\
\text { diabetes }\end{array}$ & $\begin{array}{l}\text { Surgical debridement } \\
\text { plus amphotericine-B }\end{array}$ & $\begin{array}{l}\text { Death after } 1 \\
\text { year of treat- } \\
\text { ment }\end{array}$ \\
\hline 5 & M & 62 & Sinonasal & Facial pain & $\begin{array}{l}\text { Uncontrolled } \\
\text { diabetes }\end{array}$ & $\begin{array}{l}\text { Endoscopic debride- } \\
\text { ment }\end{array}$ & Cured \\
\hline 6 & M & 44 & $\begin{array}{l}\text { Middle ear } \\
\text { and mastoid }\end{array}$ & $\begin{array}{l}\text { Ear discharge and } \\
\text { otalgia }\end{array}$ & $\begin{array}{l}\text { Acute myeloid } \\
\text { leukemia }\end{array}$ & $\begin{array}{l}\text { Mastoid exploration } \\
\text { with debridement plus } \\
\text { amphotericine-B }\end{array}$ & Cured \\
\hline 7 & M & 29 & Palate & Palatal ulcer & $\begin{array}{l}\text { Acute lympho- } \\
\text { blastic leukemia }\end{array}$ & $\begin{array}{l}\text { Surgical debridement } \\
\text { plus amphotericine-B }\end{array}$ & Cured \\
\hline 8 & M & 49 & Sinonasal & Headache & $\begin{array}{l}\text { Uncontrolled } \\
\text { diabetes }\end{array}$ & $\begin{array}{l}\text { Endoscopic debride- } \\
\text { ment plus amphoteri- } \\
\text { cine-B }\end{array}$ & Cured \\
\hline
\end{tabular}

